\title{
Rational prescribing of antibiotics in children under 5 years with upper respiratory tract infections in Kintampo Municipal Hospital in Brong Ahafo Region of Ghana
}

\author{
Abdul-Nasiru Sumaila ${ }^{1}$ and Philip Teg-Nefaah Tabong ${ }^{2^{*}}$
}

\begin{abstract}
Objective: The aim of the study was to assess the rational use of antibiotics in children with URTIs in the Kintampo Municipal Hospital in Ghana.

Results: A total of 839 medicines were prescribed, 237 were antibiotics. The mean number of medicines prescribed per patient encounter was 3.1. The percentage of patient encounters with antibiotics was 28.2 and $0.4 \%$ for injections. The percentage of medicines prescribed by generic was $93.8 \%$ and from the essential medicines list was $94.9 \%$. Ninety-two of patients received amoxicillin. Polypharmacy was common as prescriptions with five to six medicines per patient encounter was found. Some prescribers are not following the WHO/INRUD requirement of prescribing medicines in their generic and from the essential medicine list of the country.
\end{abstract}

Keywords: Rational, Medicine, Antibiotics, Children, Upper respiratory tract infection, Ghana

\section{Introduction}

In the last decades, medicines have had an unprecedented positive effect on health, leading to decline in mortality, disease burden and overall quality of life [1]. The rational use of medicines is regarded as a measure of good clinical practice. The inappropriate use of medicines especially antibiotics have negative consequences on the quality of care and can lead to antibiotic- resistance strains of micro-organisms [2-5]. The conference of experts on the rational use of medicines (RUM), convened by the World Health Organization (WHO) in Nairobi in 1985 defined the RUM as giving patients medicines that are appropriate to their clinical needs, in doses that meet their own individual requirements for an adequate period of time, and at the lowest cost to them and their community. In view of this, the use of medicines that do not meet the needs of patients in terms of disease condition, dose,

\footnotetext{
*Correspondence: philgh2001@yahoo.com

2 Department of Social and Behavioural Sciences, School of Public Health, University of Ghana, Legon, Accra, Ghana

Full list of author information is available at the end of the article
}

frequency and duration of therapy is described as inappropriate use of medicines [2]. This notwithstanding, studies have showed a high prevalence of antibiotic use among children under 5 with an estimate rate of 2.2 prescriptions per person per year $[6,7]$. Though there are no age-specific disaggregated data, earlier studies have found that antibiotic use in Ghana to be between 11.9 and $60.7 \%[8-10]$.

Upper respiratory tract infections (URTIs) are infectious diseases of the upper respiratory tract and include condition such as common cold, influenza, pharyngitis, otitis media, tonsillitis and sinusitis [11]. However, common cold is reported as the most prevalent accounting for about $80 \%$ of URTIs [12]. URTIs are mostly managed symptomatically with basic analgesics to relief fever, increased fluid intake and with nasal decongestants [13] because they are mostly viral in origin and many (about 90\%) resolve without any intervention [12].

URTIs are very common among paediatric population and therefore constitute a major target for inappropriate use of antibiotics. As a measure to help reduce the 
inappropriate use of antibiotics, the WHO has advocated for the use of essential medicine list and other policy guidelines for the use of medicines including antibiotics [14-16]. The Ghana National Drug Programme has developed and distributed the essential medicines list (EML) and Standard Treatment Guidelines (STGs) to all public health institutions over the years [17]. The national drug treatment guideline requires that all prescription should be generic and should be listed in the essential medicine list of the country [17]. The STGs provides for age and disease-specific doses and duration of treatment. The aim of this study was to assess rational use of medicine among paediatric patients in the Kintampo Municipal hospital.

\section{Main text}

\section{Materials and methods}

Study design

We reviewed medical records of children under 5 years who attended the out-patient department of Kintampo Municipal Hospital with URTIs between the 1st of January, 2009 and 31st December, 2014 using a WHO checklist on rational use of medicine.

\section{Study area}

The Kintampo Municipality is one of the 28 districts in the Brong Ahafo region of Ghana. The municipality has a population of 111,263 [18]. The Kintampo Municipality has one District hospital of 125 bed capacity, two Health centres, two Rural clinics, one Community-based Health Planning Services (CHPS) compound and one Maternity home.

\section{Sample size determination}

We used Yamane's formula (1967) for population proportion to compute the sample size for this study;

$$
\mathrm{n}=\frac{N}{1+N\left(e^{2}\right)}
$$

where $\mathrm{n}=$ minimum sample size, $\mathrm{N}=$ population size of $648, \mathrm{e}=$ level of precision which was set at $5 \%$. Substituting the above into Eq. 1 resulted in a sample size of 248 . However, it was increased by $10 \%$ to 270 .

\section{Data collection}

A systematic random sampling procedure was used. The sampling interval of two was obtained by dividing the study population $(\mathrm{N})$ by the sample size (n) [19]. We used this sampling interval to sample patients and retrieved their medical records for the review.

\section{Study variables}

We extracted the following variables from patients primary medical records: diagnoses (primary and secondary) according to the International Classification of Diseases (ICD-9), age, sex, and prescription of antibiotic at that visit (whether prescribed or not, and if so, the type of antibiotic selected), dose, frequency and duration.

\section{Data analysis}

The data extracted were entered into STATA 13 and analysed. The results were than compared with WHO benchmark indicators. Appropriateness of treatment was determined by the extent of adherence to the Ghana STG and EML [20] using the criteria recommended by Kunin et al. [21] and Deshmuch et al. [22].

\section{Results \\ Type of URTIs and antibiotics used}

The minimum age was 0.5 months (15 days), the maximum age was 57 months with an average age of $18.3 \pm 13$ months. Children aged $1-5$ years (1259 months) accounted for majority of patients (62.6\%). Only 3 patients were less than 1 month (1.1\%). Out of the 270 patients, $140(52.0 \%)$ were males. Among the 270 patients, the most common URTI was common cold (52.6\%). However, 17 patients had conditions which did not fit into the classification criteria for any URTIs and were therefore described as non-specific.

A total of 839 medicines were prescribed for the 270 patients with no patient reporting multiple attendance for URTI. Two hundred and seven (237) antibiotics were prescribed per patient encounter; penicillin (58\%), cephalosporins (19\%) and macrolides (10\%). Amoxicillin (38.8\%), cefuroxime (18.6\%) and amoxicillin + clavulanic acid $(17.3 \%)$ were the commonly prescribed antibiotics (Table 1).

Sixty-two (43.7\%) of patients with common cold received amoxicillin, $5(3.5 \%)$ received amoxicillin with clavulanic acid and $6(4.2 \%)$ received azithromycin and cefuroxime whilst $32(22.6 \%)$ did not receive any antibiotic. Among patients with otitis media, majority, 23 (33.3\%) were given amoxicillin + clavulanic acid whilst $21(30.4 \%)$ received amoxicillin. Patients with pharyngitis received amoxicillin with clavulanic acid (47.8\%).

\section{Assessment of rational prescribing}

The mean number of medicines per patient encounter was 3.1 which was higher than the WHO standard of $\leq 2$ medicines per patient encounter. The prevalence of antibiotic use for URTIs was $28.6 \%$. Prescription by generic 
Table 1 Antibiotics prescribed for the management of URTIs

\begin{tabular}{lcc}
\hline Antibiotic $(\mathbf{n}=\mathbf{2 3 7})$ & Frequency (F) & $\begin{array}{c}\text { Percentage } \\
(\mathbf{F} \times \mathbf{~ 1 0 0 / n )}\end{array}$ \\
\hline Penicillins & & \\
Amoxicillin suspension & 92 & 38.8 \\
Amoxicillin + clavulanic acid & 41 & 17.3 \\
$\quad$ suspension & & 1.7 \\
$\quad$ Flucloxacillin suspension & 4 & \\
Cephalosporins & & 18.6 \\
Cefuroxime suspension & 44 & 0.4 \\
Ceftriaxone injection & 1 & 7.2 \\
Macrolides & & 3.0 \\
Azithromycin suspension & 17 & \\
$\quad$ Erythromycin suspension & 7 & 8.9 \\
Sulphonamides & & 4.2 \\
Cotrimoxazole suspension & 21 & 12.2 \\
Others & 10 & \\
No antibiotic & 33 & \\
\hline
\end{tabular}

and from the essential medicines list were 93.8 and $94.9 \%$, respectively (Table 2 ).

About $93.0 \%$ of prescriptions had appropriate doses, 95.6\% were appropriate in frequency and $96.7 \%$ had appropriate duration of treatment (Table 3).

\section{Discussion}

This study revealed that common cold was the most diagnosed URTI, followed by otitis media. Common cold accounted for more than half of the diagnoses of the total prescriptions. This findings as agrees with literature that showed that children tend to develop 3-8 bouts of common cold in a year and this even tends to increase for children who attend daycare or preschool [23, 24]. Out of the 142 URTIs diagnosed with common cold, 110 (77.4\%) were given antibiotics. In Northern Tanzania, it was found that about $68.9 \%$ of children under 5 received antibiotic [25] despite the fact this condition in mainly viral and therefore the use of antibiotic is inappropriate. Generally, it is recommended that children with common cold should managed with nasal decongestant [26], antihistamine [27] and zinc [28] as these help to relief symptom leading to spontaneous recovery. The use of intranasal ipratropium bromide has also be found to be very useful in relieving symptoms of common cold [29]. The findings of study underscore the need to sensitize prescribers on rational use of medicines especially for common cold.

The study revealed three main classes of antibiotics which were commonly used to manage URTIs in children in the hospital. These classes were the penicillins, cephalosporins and the macrolides and similar findings have been reported in a study in South Western Nigeria [30]. The most prescribed class was the penicillins specifically amoxicillin and amoxicillin + clavulanic acid. Amoxicillin is the first line antibiotic in the management of URTIs according to the Standard Treatment Guideline of Ghana [31].

Furthermore, the study revealed a 3.1 average number of medicines prescribed per patient encounter, implying that, patients were likely to receive three medicines per visit. The WHO indicator tools for rational prescribing

Table 2 Comparison between the uses of medicine for URTIs in the study are against the WHO standard

\begin{tabular}{lll}
\hline Prescribing indicator & Value & WHO standard \\
\hline Total number of patients prescriptions analysed & 270 & $\geq 100$ \\
Total number of medicines prescribed & 839 & - \\
Average number of medicines prescribed per encounter & 3.1 & $\leq 2$ \\
\% Medicines prescribed by generic & 93.8 & 100 \\
\% Patient encounters with antibiotics prescribed & 28.2 & $\leq 30$ \\
\% of patient encounters with injections prescribed & 0.4 & $\leq 10$ \\
\% of medicines prescribed from essential medicines list or formulary & 94.9 & 100 \\
\hline
\end{tabular}

Table 3 Distribution of prescriptions according to appropriateness

\begin{tabular}{lllll}
\hline Parameter & No. appropriate & Prescriptions $(\mathbf{N}=\mathbf{2 7 0})$ & \% inappropriate \\
\cline { 3 - 4 } & & \% appropriate & No. inappropriate & 7.0 \\
\hline Dose & 251 & 93.0 & 19 & 4.4 \\
Frequency & 258 & 95.6 & 12 & 3.3 \\
Duration & 261 & 96.7 & 9 & \\
\hline
\end{tabular}


however requires that only one or two medicines are prescribed per patient encounter [32]. This finding suggests the presence of poly pharmacy. A study carried out at the Ghana Police Hospital revealed a similar finding of 3.7 [33]. Similar findings have been reported in studies in Uganda (2.6) [34] and Jordan (2.4) [35].

The findings of this study further showed that the percentage of medicines prescribed by generic wad $93.8 \%$ which is less than the requirement that all medicines should be prescribed in generic. This further call for refresher training for prescribers to conform to the standards in prescribing medicines for patients as rational use of medicines has become an indicator for measuring quality of health care [36-38].

The percentage of patient encounters with antibiotics prescribed was $28.6 \%$. This is within the range of $\leq 30 \%$ optimal, WHO standards and therefore tends to suggest a prudent use of antibiotics in Kintampo Municipal Hospital. Such a judicious use of antibiotics will go a long way to minimize antibiotic resistance and serious adverse effects $[39,40]$. A percentage of $0.4 \%$ obtained for patient encounters with injections is also within WHO/INRUD Standard of $\leq 10 \%$. This is however higher than the findings of a study conducted in Ethiopia that reported a lower percentage of $0.04 \%$ [41]. Globally, the use injections should be kept to the minimum because of the increasing risk of transmission of HIV, hepatitis and other blood related diseases through injection [42-44]. The low rate of injection use is also likely to reduce the risk of anaphylactic shock, tissue necrosis and sepsis in patients [45-47].

The findings showed that $94.9 \%$ for medicines prescribed from the essential medicines list falls short of the optimal WHO/INRUD standard of $100 \%$. This is however higher than a study conducted in Ghana in 2014 which found a $53.6 \%$ adherence to WHO/INRUD requirement [33]. This finding also indicate the need for training and development of quality assurance programmes. In Europe, quality assurance programmes and public campaigns have been developed and launched to improve the use of antibiotics in primary care [48-50]. This strategy could be harnessed for Ghana to improve rational use of antibiotics and adherence to standards in the use of medicines.

\section{Conclusions}

This study conclude that the overuse of antibiotics for URTIs was common in Ghana. The penicillins and cephalosporins are the most preferred antibiotics prescribed for the management of upper respiratory tract infections in children under 5 years. Some prescribers are not following the WHO/INRUD requirement of prescribing medicines in their generic and from the essential medicine list of the country.

\section{Limitation}

The study was carried out in only one health facility within the municipality and region, hence the conclusions should be interpreted in the context of the limited scope of the research.

\section{Abbreviations}

INRUD: International Network for Rational Use of Drugs; RUM: rational use of medicine; STG: Standard Treatment Guideline; URTI: upper respiratory tract infection; WHO: World Health Organisation.

\section{Authors' contributions}

Conceived and designed the experiments: ANS, PT-NT. Performed the experiments: ANS Analyzed the data: ANS, PT-NT. Contributed reagents/materials/ analysis tools: ANS, PT-NT. Wrote the paper: ANS, PT-NT. All authors read and approved the final manuscript.

\section{Author details}

1 Pharmacy Department, Jema District Hospital, Ghana Health Services, Accra, Brong Ahafo Region, Ghana. ${ }^{2}$ Department of Social and Behavioural Sciences, School of Public Health, University of Ghana, Legon, Accra, Ghana.

\section{Acknowledgements}

We wish to thank the Medical Superintendent of the Kintampo Municipal Hospital and medical records staff for the assistance.

\section{Competing interests \\ The authors declare that they have no competing interests.}

\section{Availability of data and materials}

The data sets during and/or analyzed during the current study are available from the corresponding author on reasonable request.

\section{Consent to publish}

Not applicable.

\section{Ethics approval and consent to participate}

The proposal for this study was reviewed and approved by the Ethics and Review Committee of the Ghana Health Service (GHS-ERC 104/02/15). We also received administrative permission from the health facility to review patient records and use the data for this study.

\section{Funding}

This study was conducted as part of the requirements for the award of a Master of Public Health Degree by ANS. He did not receive any funding from any institution.

\section{Publisher's Note}

Springer Nature remains neutral with regard to jurisdictional claims in published maps and institutional affiliations.

Received: 11 May 2018 Accepted: 26 June 2018

Published online: 04 July 2018

\section{References}

1. WHO. The pursuit of responsible use of medicines: sharing and learning from country experiences. Vet Rec. 2012;169:78.

2. Bbosa GS, Wong G, Kyegombe DB, Ogwal-Okeng J. Effects of intervention measures on irrational antibiotics/antibacterial drug use in developing countries: a systematic review. Health. 2014;6:171-87.

3. Goossens $H$, Ferech M, Vander Stichele R, Elseviers M. Outpatient antibiotic use in Europe and association with resistance: a cross-national database study. Lancet. 2005;365:579-87. 
4. Friedman BC, Schwabe-Warf D, Goldman R. Reducing inappropriate antibiotic use among children with influenza infection. Can Fam Physician. 2011;57:42-4.

5. Gebeyehu E, Bantie L, Azage M. Inappropriate use of antibiotics and its associated factors among urban and rural communities of Bahir Dar city administration, northwest Ethiopia. PLoS ONE. 2015;10:e0138179.

6. Marc C, Vrignaud B, Levieux K, Robine A, Guen CG-L, Launay E. Inappropriate prescription of antibiotics in pediatric practice. $J$ Child Health Care. 2016:20:530-6.

7. Rossignoli A, Clavenna A, Bonati M. Antibiotic prescription and prevalence rate in the outpatient paediatric population: analysis of surveys published during 2000-2005. Eur J Clin Pharmacol. 2007;63:1099-106.

8. Apenteng JA, Addy BS, Onwukwe EO, Brookman-amissah G. Antibiotics prescribing patterns and incidence of respiratory tract infection in children under five years: a study in two hospitals in Accra, Ghana. Int J Med Med Sci. 2018;10:47-58.

9. Prah J, Kizzie-Hayford J, Walker E, Ampofo-Asiama A. Antibiotic prescription pattern in a Ghanaian primary health care facility. Pan Afr Med J. 2017;28:1-10.

10. Ahiabu MA, Tersbøl BP, Biritwum R, Bygbjerg IC, Magnussen P. A retrospective audit of antibiotic prescriptions in primary health-care facilities in Eastern Region, Ghana. Health Policy Plan. 2016;31:250-8.

11. NHS. Respiratory tract infections - antibiotic prescribing. NICE Clin Guidel. 2008:69:1-240.

12. Cotton M, Innes S, Jaspan H, Madide A, Rabie H. Management of upper respiratory tract infections in children. South Afr Fam Pract. 2014;50:6-12.

13. Thi D, Nguyen K, Leung KK, Mcintyre L, Ghali WA, Sauve R. Does integrated management of childhood illness (IMCI) training improve the skills of health workers? A systematic review and meta-analysis. Plos ONE. 2013;8:e66030.

14. Braine T. WHO to launch first essential medicines list for children. Bull World Health Organ. 2007;85:249-50.

15. WHO. WHO model list of essential medicines. Children. 2010;19:1-43.

16. WHO. WHO model list of essential medicines. 18th ed. Geneva: WHO; 2013.

17. GHS. Ghana essential medicines list. Accra: Ghana Health Service; 2004.

18. Ghana Statistical Service. Population and housing census. Ghana Stat Serv. 2010:2012:1-117.

19. Bowling A. Research methods in health: investigating health and health service. 4th ed. England: Open University Press; 2014

20. $M O H(G N D P)$. Standard treatment guidelines. 6th ed. Accra: MOH(GNDP); 2010.

21. Kunin C, Tupasi T, Craig W. Use of antibiotics. A brief exposition of the problem and some tentative solutions. Ann Intern Med. 1973;79:555-60.

22. Deshmukh A, Ghadlinge M, Tamboli S, Deshmukh J, Chhabra R. Study of rationality and utilization pattern of antimicrobials in ear, nose, throat outpatient department of Tertiary Care Hospital, Nanded. Int J Basic Clin Pharmacol. 2015;4:734-8.

23. Amra B, Sohrab-Pour H, Shirani S, Golshan M. Prevalence of the common cold symptoms and associated risk factors in a large population study. Tanaffos. 2006:5:13-7.

24. Rerksuppaphol S, Rerksuppaphol L. A randomized controlled trial of chelated zinc for prevention of the common cold in Thai school children. Paediatr Int Child Health. 2013;33:145-50.

25. Gwimile JJ, Shekalaghe SA, Kapanda GN, Kisanga ER. Antibiotic prescribing practice in management of cough and/or diarrhoea in Moshi Municipality, Northern Tanzania: cross-sectional descriptive study. Pan Afr Med J. 2012;12:103.

26. Taverner D, Latte J. Nasal decongestants for the common cold. Rev: Cochrane Database Syst; 2007.
27. De Sutter AIM, Saraswat A, van Driel ML. Antihistamines for the common cold. Cochrane Database Syst Rev. 2015;11:CD009345.

28. Singh M, Das RR. Zinc for the common cold. Evid Based Child Health. 2012;314:1235-308.

29. AlBalawi ZH, Othman SS, AlFaleh K. Intranasal ipratropium bromide for the common cold. Cochrane Database Syst. Rev. 2013;7:1-36.

30. Joseph F, Oladele O, Oludare O, Olatunde O. Drug prescribing pattern for under-fives in a paediatric clinic in south-western Nigeria. Ethiop J Health Sci. 2015:25:73.

31. Ghana National Drugs Programme (GNDP), Ministry of Health. STG. Standard Treatment Guidelines (Ministry of Health-Ghana). 6th ed. Accra: Ghana National Drugs Programme (GNDP), Ministry of Health; 2010.

32. WHO (World Health Organization). Guide to good prescribing. Can Med Assoc J. 1993;2:383-90.

33. Afriyie DK. A description of the pattern of rational drug use in Ghana Police Hospital. Int J Pharm Pharmacol. 2014;3:143-8.

34. Mcgaughey N. Prescribing practices and polypharmacy in Kitovu Hospital, Uganda. East Cent Afr J Pharm Sci. 2010;13:66-71.

35. Al-Niemat SI, Aljbouri TM, Goussous LS, Efaishat RA, Salah RK. Antibiotic prescribing patterns in outpatient emergency clinics at Queen Rania Al Abdullah II Children's Hospital, Jordan. Oman Med J. 2013;2014:250-4.

36. Ferreira MBC, Heineck I, Flores LM, Camargo AL, Dal Pizzol TDS, Torres ILDS, et al. Rational use of medicines: prescribing indicators at different levels of health care. Braz J Pharm Sci. 2013:49:329-40.

37. Wagner AK, Quick JD, Ross-Degnan D. Quality use of medicines within universal health coverage: challenges and opportunities. BMC Health Serv Res. 2014;14:357.

38. Laing R, Waning B, Gray A, Ford N, Hoen ET. 25 Years of the WHO essential medicines lists: progress and challenges. Lancet. 2003;361:1723-9.

39. Ventola CL. The antibiotic resistance crisis. Pharm Ther. 2015;40:277-83.

40. French $\mathrm{GL}$. The continuing crisis in antibiotic resistance. Int J Antimicrob Agents. 2010;36:S3-7.

41. Sebsibie G, Gultie T. Retrospective assessment of irrational use of antibiotics to children attending in Mekelle general hospital. Sci J Clin Med. 2014:3:46-51.

42. Altaf A, Ali Shah S, Khamassi S. Preventing transmission of hepatitis $C$ due to unsafe injections should be a priority for Pakistan. J Pak Med Assoc. 2014:64:239-41.

43. Gisselquist DP. Estimating HIV-1 transmission efficiency through unsafe medical injections. Int J STD AIDS. 2002;13:152-9.

44. White RG, Ben SC, Kedhar A, Orroth KK, Biraro S, Baggaley RF, et al. Quantifying HIV-1 transmission due to contaminated injections. Proc Natl Acad Sci. 2007;104:9794-9.

45. Limsuwan T, Demoly P. Acute symptoms of drug hypersensitivity (urticaria, angioedema, anaphylaxis, anaphylactic shock). Med Clin. 2010:94:691-710.

46. Canabal J, Caballero T, Caminoa M, Fiandor A, Quirce S, Cabañas R. Anaphylactic shock caused by a hidden allergen in blood sausage. J. Invest Allergol Clin Immunol. 2016;26:200-1.

47. Prusakowski MK, Chen AP. Pediatric sepsis. Emerg Med Clin N Am 2017:35:123-38

48. Welschen I, Kuyvenhoven M, Hoes A, Verheij T. Antibiotics for acute respiratory tract symptoms: patients' expectations, GPs' management and patient satisfaction. Fam Pract. 2004;21:234-7.

49. Goossens H, Guillemot D, Ferech M, Schlemmer B, Costers M, Van Breda $\mathrm{M}$, et al. National campaigns to improve antibiotic use. Eur J Clin Pharmacol. 2006;62:373-9.

50. Huttner B, Harbarth S. 'Antibiotics are not automatic anymore'-The French national campaign to cut antibiotic overuse. PLoS Med. 2009:6:e1000080. 